\title{
Application of computer networks in college students' psychological File Management
}

\author{
ChangXiang.Jiang ${ }^{1, a}$, JunHua. Zhou ${ }^{2, b}$ \\ ${ }^{1}$ Jiangxi Science \& Technology Normal University, Nanchang, Jiangxi, 330013, P.R. China \\ 2 Jiangxi Vocational Academy of Art, Nanchang, Jiangxi, 330013, P.R. China \\ aMAME2013@163.com, bHul2016@126.com
}

Keywords: Computer network, IT, records management.

\begin{abstract}
Students mental health problems directly related to the chance of success in college students, so the university attaches great importance to college students' psychological health education, and the establishment of college students is one of the important work of mental file strengthen mental health education colleges. With the rapid spread of information technology and the rapid development of computer networks, to bring a new way for college students' psychological records management work. This paper analyzes the current situation and problems of college students' psychological records management, and proposed the full use of computer network technology and mobile communications technology, and efficient records management college students to carry out the work.
\end{abstract}

\section{Introduction}

With the rapid development of information technology and the rapid spread of computer networks, especially the rapid popularization of mobile networks, QQ, micro letters, e-mail and a variety of APP application has gradually integrated into the lives of college students, college students gradually became college life part, changing lifestyle of college students learning to students bring a lot of convenience, but also bring a range of psychological problems, can not be ignored. Strengthening college students' mental health records, monitoring students' psychological changes, to guide the growth of students' mental health is an important work in colleges and universities to strengthen the mental health education.

The traditional file management colleges, there are many psychological deficiencies, the authors analyzed the traditional psychological problems in college archives management. Proposed: full use of computer network technology, is an important way to improve the management level of Psychological Archives.

\section{Computer Network Technology Overview}

\subsection{Traditional computer network}

Computer network technology and communication technology is the product of the combination of computer technology. The computer network is a network in accordance with the agreement, will be a different location, function relatively independent computers connected to each other, and managed by a dedicated network operating system to achieve resource sharing and collaborative work systems.

Different Location: refers to a computer network in which the computer is usually different physical locations, it is possible in a room or a building where there may be scattered on the earth, thousands of miles apart. For example, when we visited WEB service via the Internet, the server is accessed and the computers we use, in the ground position is different, and for our users, we do not care about their location.

Function relatively independently: refers to a computer which is connected to a computer network is first fully functional, has its own hardware and software, there are no dependencies between them. 
In other words, each computer can be used both for networking in the network can also be run from the network as a stand-alone. These computers have an operating system, there are input, output, operation function.

Computer network set up for the purpose of sharing resources and information exchange. Both shared resources may be hardware resources, there may be software resources. Each computer, for example, some small office, only one printer, enabling printer sharing over a computer network, making the office computer network can be like using a printer connected to their computer, like to use this shared printer, which is typical hardware resource sharing. Simple program another example, some computers with no hard disk workstation itself, which only solidified in the ROM to start the computer and the computer connected to the network, these software resources of a computer connected to the network provided by the computer network using the server to complete the job characteristics in a resource-sharing software.

Function of the transmission medium is to achieve functional independence, geographically dispersed physical connection to the computer. Wired transmission media and wireless transmission media. Common wired transmission medium cables, telephone lines, twisted pair. Signal transmission medium can be transferred from one party to another.

\subsection{Development of computer networks}

Computer networks from generation to develop, in general, can be divided into four phases.

Stage 1: the late 1960s to the early 1970s for the development of computer network infancy. Its main features are: to increase the computing power and resource sharing system, the small computer connected into experimental networks. The first remote packet switching network called ARPANET, was built by the US Department of Defense in 1969, first achieved by communication networks and network resources constitute a composite computer network system. Flag computer networks generate real, ARPANET is a typical representative of this stage.

Stage 2: In the late 1970s, is a local area network (LAN) important stage of development, and its main features are: local area network as a new computer architecture began to enter the industrial sector. LAN technology is switched communications network and I / O bus architecture of computer system from a remote packet derived. In 1976, Palo Alto Research Center, Xerox's US launch Ethernet (Ethernet), which successfully adopted the basic principles of the University of Hawaii ALOHA radio network system, making the competition to become the first bus-type local area network. In 1974, the University of Cambridge Computer Institute developed the famous Cambridge ring LAN (Cambridge Ring). The success of these networks to achieve, on the one hand to produce marked local area network, on the other hand, they form an Ethernet ring network, and to the development of future LAN functions as navigation.

Stage 3: The entire 1980s was the development of local area network computer era. Its main features are: LAN ISO's ability to fully realize the OSI protocol communication mode from hardware. Integrated computer LAN and interconnect products, making local interconnect LAN, LAN interconnection with various hosts, as well as LAN and WAN interconnection technology becomes more mature. Integrated business data communications network (ISDN) and intelligent network (IN) development, marking the rapid development of the local area network. February 1980, IEEE (Institute of Electrical and Electronics Engineers) under the 802 LAN Standards Committee was set up, and have put forward a draft IEEE801.5 802.6 and other local area network standard, which most of what has been the International Organization for Standardization (ISO) formally recognized. As an international standard local area network, it marks the LAN protocols and standardized identification, laid the foundation for the further development of the LAN.

Stage 4: the early 1990s to the present is the stage of rapid development of computer network, and its main features are: computer networking, collaborative computing capacity development and global interconnection network (Internet) are prevalent. The development of computers has been fully integrated with the network, the concept of "network is the computer" slogan. Currently, computer networks have truly entered all walks of life, as adopted by all sectors of society. In addition, the virtual network technology, FDDI and ATM applications, the network technology to flourish and to market quickly, into civilian life. 


\subsection{The next generation of computer networks (NGN)}

IP technology as the core of the Internet in the late 90s of the last century has been the rapid development, the growth trend is explosive. Large-scale application of IP telephony proved the possibility of a strong IP network to carry telecommunications services, in this context, it is proposed the concept of next generation network (NGN) in.

Next Generation Network (NGN) Basic features:

Next Generation Network (NGN) based on packet switching technology, and its essence is to improve the current IP technology allows a computer network capable of carrying more business.

Next Generation Network (NGN) using a layered architecture: network structure responsible for making simple words, the network will be more flexible, network upgrades easier, but also conducive to the rapid deployment and implementation of third-party services.

Next Generation Network (NGN) services provided will be more diversified, in addition to traditional voice and text services, will also provide a growing number of multimedia services, streaming media services, and other services.

Next Generation Network (NGN) is also able to achieve with traditional network interoperability, with operability and manageability features.

\section{File Management University Mental Problems}

University Mental records management is an important part of college students' psychological health education. Level of Psychological records management level is directly related to the healthy growth of college students. Currently, there are more psychological problems college archives management.

\subsection{Low level of business psychology archives staff.}

Although there are many colleges and universities recognize the importance of Psychological archival work, the establishment of a mental archives, arranged a number of personnel engaged in the construction and management of mental archives work, but these tend by a college student counselor, teacher or ideological and political records management staff as a graduate, few thinker psychological knowledge, but also understands pedagogy and archives professional personnel engaged in complex mental archives. The level of business-related staff determines the mental archives building, implementation of psychological measurement, analysis of the situation of psychological measurement table, judgment, therefore, the level of business-related personnel files directly determines the quality of mental work.

\subsection{There is no clear specification psychological Archives.}

At present, the university's psychological records management in their own array of conditions, whether it is professional leadership archives department, or the relevant departments of higher education have no clear mental archives specification. The basic principles of Psychological archival work, engaged in the task system construction sector mental archives, archives in the quality of cadres mental demands, mental archives collection, sorting, editing and research and academic psychology archives, etc., there is no uniform requirement.

Current college students' psychological archives established measurement tools mostly use foreign psychological measurement tools, such as the common symptoms checklist, Cattell 16 Personality Factor Questionnaire and so on. By actual measurement, we found that these psychometric instruments are not entirely suitable for Chinese students, and therefore, the deviation of the findings of the reliability and validity of the actual situation will be relatively large. Mental condition of the individual is a dynamic process, the results of psychological measurement does not reflect all of the psychological state of the individual, only one aspect of a general description of the psychological state of the individual measurements.

\subsection{Archives range of psychological limitations.}

Mental condition of the individual is a dynamic process of change, mental archives how to accurately reflect the changes in students' individual psychological characteristics and each stage is a subject worthy of study. Many of Psychological Archives range is limited to universities, which as a 
complete mental archives system, it is not enough, we must take into account other environmental and social factors other than the university, such as family and community.

\subsection{Function can not fully exert psychological files, utilization needs to be improved.}

Many colleges and universities to establish psychological files tend to be strict sequestration, due to objective conditions, only a handful of teachers engaged in psychological counseling when necessary to view, students, school teachers can not get other information, let alone individuals tested conducted by one of the "feedback" and "interaction" was.

\section{Use of computer networks to improve the level of Psychological Archives Management}

Full use of computer network technology can solve some of the problems of Psychological records management currently exist in the work to improve the level of Psychological Archives Management.

4.1 Use of computer network technology can improve the mental archives staff professional level.

File management knowledge is constantly developing progress, which requires records management staff of the times, constantly learning new knowledge. However, due to various factors of work, family, etc., to the knowledge of records management staff has caused difficulties. An important application of computer network is the online learning. Mental archives staff through online learning, take advantage of free time, to enrich their professional knowledge and improve their professional level.

\subsection{Use of computer networks to build appropriate psychometric instruments.}

The conventional case, and are based on a questionnaire to measure students' psychological problems. In this way, under normal circumstances are in a class with students answer, students are more likely to be affected by the surrounding environment, thus affecting students' responses to the questionnaire. If the use of computer networks, the students answered a questionnaire on without time and space constraints, thereby enhancing the authenticity of the results obtained.

\subsection{Use of computer networks, can break the limitations of the scope of mental archives.}

Through a computer network, you can make the student's parents, siblings and even former classmates are involved in psychological investigations in the past, but not like before, the object of the survey confined to the students. Such a survey is more comprehensive, allowing the establishment of a more realistic reflection of mental archives students real psychological condition.

\section{Conclusion}

Computer network for college psychology Archives unprecedented convenience. However, we should pay attention to issues related to network security, especially students of psychology privacy protection.

This article research university archives "Practice and Exploration of Psychological Archives of Jiangxi Province" (number: jxgxdakt-2012071), Jiangxi Province, one of the research results.

\section{References}

[1]. had Ze Xin Wen Yi Ai research students psychological records management system feedback mechanism [J]. Guangxi College of Education, 2007 (6).

[2]. Wang Xiaoqi, Wang Xueying. Mental Health Survey and filing Problems and Countermeasures [J]. Psychology, 2011 (10).

[3]. Jin Zhiming, Li Jianping Investigation and Reflection on School Mental Health Education (five) [J] China Education Daily, 1999 (1): 27. 